\title{
Genetics and fine mapping of a purple leaf gene, BoPr, in ornamental kale (Brassica oleracea L. var. acephala)
}

Xiao-ping Liu, Bao-zhen Gao, Feng-qing Han, Zhi-yuan Fang, Li-mei Yang, Mu Zhuang, Hong-hao Lv, Yu-mei Liu, Zhan-sheng Li, Cheng-cheng Cai, Hai-long Yu, Zhi-yuan Li and Yang-yong Zhang*

\begin{abstract}
Background: Due to its variegated and colorful leaves, ornamental kale (Brassica oleracea L. var. acephala) has become a popular ornamental plant. In this study, we report the fine mapping and analysis of a candidate purple leaf gene using a backcross population and an $F_{2}$ population derived from two parental lines: W1827 (with white leaves) and P1835 (with purple leaves).

Results: Genetic analysis indicated that the purple leaf trait is controlled by a single dominant gene, which we named BoPr. Using markers developed based on the reference genome '02-12', the BoPr gene was preliminarily mapped to a 280-kb interval of chromosome C09, with flanking markers M17 and BolD4714 at genetic distances of $4.3 \mathrm{CM}$ and $1.5 \mathrm{cM}$, respectively. The recombination rate within this interval is almost 12 times higher than the usual level, which could be caused by assembly error for reference genome '02-12' at this interval. Primers were designed based on 'TO1000', another B. oleracea reference genome. Among the newly designed InDel markers, BRID485 and BRID490 were found to be the closest to $B \circ P r$, flanking the gene at genetic distances of $0.1 \mathrm{cM}$ and $0.2 \mathrm{cM}$, respectively; the interval between the two markers is $44.8 \mathrm{~kb}$ (reference genome 'TO1000'). Seven annotated genes are located within the $44.8 \mathrm{~kb}$ genomic region, of which only B09g058630 shows high homology to AT5G42800 (dihydroflavonol reductase), which was identified as a candidate gene for BoPr. Blast analysis revealed that this $44.8 \mathrm{~kb}$ interval is located on an unanchored scaffold (Scaffold000035_P2) of '02-12', confirming the existence of assembly error at the interval between M17 and BolD4714 for reference genome '02-12'.
\end{abstract}

Conclusions: This study identified a candidate gene for BoPr and lays a foundation for the cloning and functional analysis of this gene.

Keywords: Ornamental kale, Purple leaf, Inheritance, Fine mapping, Candidate gene

\section{Background}

Ornamental kale (Brassica oleracea L. var. acephala) is a popular ornamental plant cultivated worldwide owing to its variegated, colorful leaves [1] and strong resistance to cold. The leaves of ornamental kale are diverse and colorful: the edges are emerald green, dark-green, gray-green, or yellow-green, and the center can be white, yellow, pink, red, purple or other complex color varieties. The leaf pattern of ornamental kale is classified as foliage leaves,

\footnotetext{
* Correspondence: zhangyangyong@caas.cn

Institute of Vegetables and Flowers, Chinese Academy of Agricultural

Sciences, 12\# ZhongGuanCun Nandajie, 100081 Beijing, People's Republic of China
}

(c) The Author(s). 2017 Open Access This article is distributed under the terms of the Creative Commons Attribution 4.0 International License (http://creativecommons.org/licenses/by/4.0/, which permits unrestricted use, distribution, and reproduction in any medium, provided you give appropriate credit to the original author(s) and the source, provide a link to the Creative Commons license, and indicate if changes were made. The Creative Commons Public Domain Dedication waiver (http://creativecommons.org/publicdomain/zero/1.0/) applies to the data made available in this article, unless otherwise stated. types. Furthermore, purple-leaf ornamental kale, which is mainly due to various anthocyanin components [2], is reported to possess strong antioxidant capacity and thus potential benefits to human health [3, 4].

Some leaf color genes have been mapped in Brassica crops. For example, the red leaf color trait is reportedly controlled by the single dominant gene $R e$ in ornamental kale, which was mapped to C09 between SSR markers C9Z90 and C9Z94, with genetic distances of $0.3 \mathrm{cM}$ and $2.0 \mathrm{cM}$, respectively [5]. In Brassica juncea, the purple leaf gene (PL) was mapped between SRAP markers ME7EM9 and ME2EM2, with genetic 
distances of $1.2 \mathrm{cM}$ and $5.5 \mathrm{cM}$, respectively [6]. A purple leaf dominant gene (BrPur) in Brassica rapa was assigned to a locus between InDel markers BVRCPI613 and BVRCPI431, with a genetic interval of $0.6 \mathrm{cM}$ [7]. An incomplete dominant gene (BnaA.PL1) for the purple leaf trait in Brassica napus has been mapped, and the possible candidate gene is predicted to encode adenosine 5'-phosphosulfate reductase [8]. Zhu et al. found the pink leaf color trait in ornamental kale to be controlled by a single semi-dominant gene mapped to C03 between SSR marker Ni2C12 and codominant SCAR marker Boac04, with genetic distances of $0.6 \mathrm{cM}$ and $2.4 \mathrm{cM}$, respectively [9].

With the development of molecular biology and the release of the $B$. oleracea draft genome $[10,11]$, uncovering the genetic basis of important traits has become a focus of theoretical and applied studies in this species. To date, many genes/QTLs have been mapped in Brassica oleracea using InDel markers, including the Fusarium wilt resistance gene $F O C 1$ [12, 13], the petal color gene $c p c-1$ [14], the yellow-green gene $y g l-1$ [15], and QTLs associated with heading traits [16], headsplitting resistance $[17,18]$, Diamondback (Plutella xylostella) moth resistance [19], and resistance to diseases such as Sclerotinia sclerotiorum [20], black rot [21, 22], and clubroot [23].

In this study, kale inbred line W1827 (with white leaves) was crossed to inbred line P1835 (with purple leaves) to construct $\mathrm{F}_{2}$ and backcross $(\mathrm{BC})$ populations, which were used for genetic analysis and fine mapping of the gene for the purple leaf trait. Genes located within the fine-mapping region were analyzed. These findings will lay a foundation for the cloning and validation of $\mathrm{BoPr}$ and will facilitate elucidation of the molecular mechanism for purple leaf formation in B. oleracea L. var. acephala.

\section{Methods}

\section{Plant materials}

The female kale inbred line W1827 ( $\mathrm{P}_{1}$, white leaf, Fig. 1a) was crossed with male kale inbred line P1835 $\left(\mathrm{P}_{2}\right.$, purple color, Fig. $1 b)$ to generate the $F_{1}$ population. The $F_{2}$ population was obtained via self-pollination of $\mathrm{F}_{1}$ plants; $\mathrm{BC}_{1} \mathrm{P}_{1}$ and $\mathrm{BC}_{1} \mathrm{P}_{2}$ populations were created by backcrossing of $F_{1} \times W 1827$ and $F_{1} \times P 1835$, respectively. All materials were from Cabbage and Broccoli Research Group, Institute of Vegetables and Flowers (IVF), Chinese Academy of Agricultural Sciences (CAAS).

\section{Genetic analysis and InDel marker development}

Leaf color was identified visually. The segregation ratios of the $\mathrm{F}_{2}$ and $\mathrm{BC}_{1}$ populations were analyzed using a Chi-square test with SAS software.

The '02-12' reference genome of cabbage was downloaded from BRAD (http://brassicadb.org) [10]; the TO1000 sequence was obtained from the genome sequence (http://plants.ensembl.org/Brassica_oleracea) [11]. The sequencing-by-synthesis method was used to re-sequence the parents at approximately $10 \times$ coverage over the entire genome [24]. This work was completed at Beijing Genomics Institute (BGI) (Shenzhen, China). For preliminary mapping, the re-sequencing data for both parents was mapped to the '02-12' reference genome of $B$. oleracea (http://brassicadb.org) to detect 3-5 bp insertion-deletion mutations between the parents. InDel primers were then designed. Due to the possible assembly error of the $02-12$ reference genome, new primers in the preliminary mapping region were designed based on the TO1000 reference genome. Primers were designed to have amplicon lengths of $100-200 \mathrm{bp}, \mathrm{GC}$ contents of $40-50 \%$ and Tm values of $52-62{ }^{\circ} \mathrm{C}$.

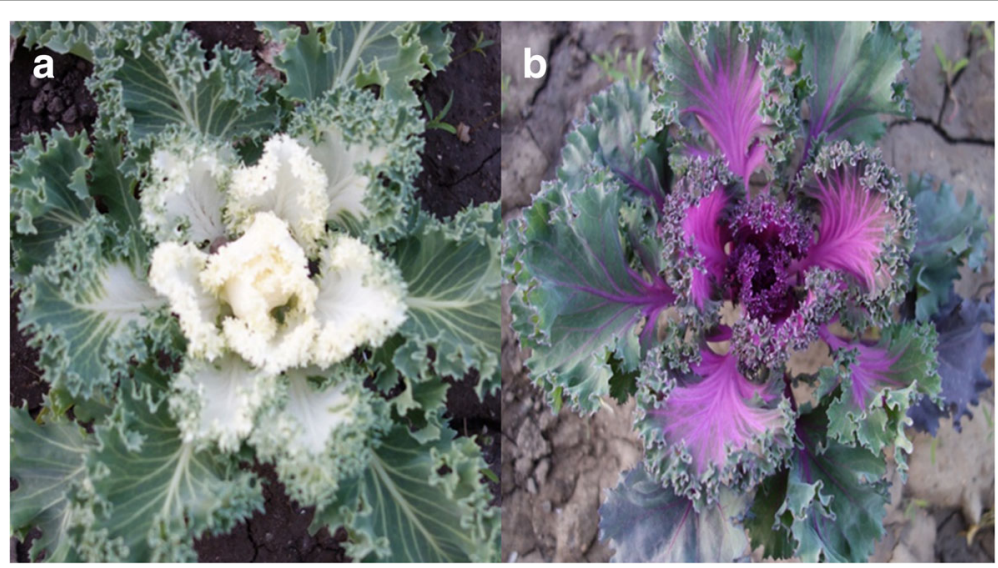

Fig. 1 Phenotypes of the parental lines. a W1827. b P1835 
DNA extraction and bulked segregant analysis (BSA) Genomic DNA was extracted from fresh leaves using a modified cetyltrimethylammonium bromide (CTAB) protocol [25]. The concentration of DNA was estimated using a spectrophotometer (BioDrop, UK) and diluted to $40-50 \mathrm{ng} / \mu \mathrm{L}$.

Ten purple-leaf $F_{2}$ individuals and ten white-leaf $F_{2}$ individuals were selected to construct two pools using the BSA method [26]. Polymorphic InDel markers between the parents were used to screen these pools, and polymorphic markers between the pools were used to examine recombination with all white-leaf individuals in the $\mathrm{F}_{2}$ and $\mathrm{BC}_{1} \mathrm{P}_{1}$ populations.

The $20 \mu \mathrm{L}$ PCR reaction mixture contained $4 \mu \mathrm{L}$ DNA template $(40-50 \mathrm{ng} / \mu \mathrm{L}), 2 \mu \mathrm{L} 10 \times \mathrm{PCR}$ buffer $\left(\mathrm{Mg}^{2+}\right.$ included), $1.6 \mu \mathrm{L}$ dNTPs (2.5 mM each), $0.8 \mu \mathrm{L}$ forward primer $(10 \mu \mathrm{M}), 0.8 \mu \mathrm{L}$ reverse primer $(10 \mu \mathrm{M}), 0.4 \mu \mathrm{L}$ Taq DNA polymerase $(2.5 \mathrm{U} / \mu \mathrm{L})$ and $10.4 \mu \mathrm{L} d \mathrm{ddH}_{2} \mathrm{O}$. Reactions were performed in a thermal cycler as follows: $94{ }^{\circ} \mathrm{C}$ for $5 \mathrm{~min}$; 35 cycles of $94{ }^{\circ} \mathrm{C}$ for $30 \mathrm{~s}, 55^{\circ} \mathrm{C}$ for $30 \mathrm{~s}$ and $72{ }^{\circ} \mathrm{C}$ for $45 \mathrm{~s} ; 72{ }^{\circ} \mathrm{C}$ for $10 \mathrm{~min}$. Amplicons were separated by $8 \%$ PAGE at $160 \mathrm{~V}$ for $1.5 \mathrm{~h}$, followed by silver staining.

\section{Data analysis}

For each marker, individuals with the W1827 allele were categorized as 'a', and individuals with the P1835 allele were categorized as ' $b$ '; those with the $F_{1}$ allele were categorized as ' $h$ '. The Kosambi mapping function was used to calculate genetic distances between markers [27], and the genetic map was constructed using MapDraw [28].

To identify probable genes associated with purple leaves, genes located within the candidate interval were analyzed based on annotations from the B. oleracea reference genome 'TO1000'.

\section{Analysis of the candidate gene}

To amplify the candidate gene Bo9g058630, primers were designed in DNAMAN 7.0 using the sequence of Bo9g058630. PCR amplification was performed using the Q5 Ultra High Fidelity DNA polymerase. The PCR amplification conditions followed the manufacturer's specifications. The annealing temperature was determined using the NEB Tm calculator (New England Biolabs, Inc.), and the elongation step was based on a rate of $30 \mathrm{~s} / \mathrm{kb}$. The candidate gene sequence was determined by Sanger sequencing of the PCR amplicons.

\section{Results}

Genetic analysis of leaf color of W1827 with P1835

Sixteen $\mathrm{F}_{1}$ individuals generated by crossing W1827 with P1835 exhibited purple leaves, indicating that the purple leaf color trait is dominant over the white-leaf trait. In the $F_{2}$ population, 258 of 1008 individuals displayed white leaves and 750 purple leaves. The Chi-square test confirmed this segregation ratio to be $3: 1$. In the $\mathrm{BC}_{1} \mathrm{P}_{1}$ population, 1040 of 2034 individuals showed purple leaves and 994 white leaves, with the Chi-square test confirming the segregation ratio to be $1: 1$. The leaves of all 200 individuals in the $\mathrm{BC}_{1} \mathrm{P}_{2}$ population were purple (Table 1). These results indicated that the purple leaf trait is controlled by a single dominant gene, which we termed $\mathrm{BoPr}$.

\section{Preliminary mapping of $\mathrm{BoPr}$}

Illumina paired-end sequencing generated reads of 9.2 $\mathrm{Gb}$ for kale inbred line W1827 and 9.9 Gb for line P1835. A total of 211 pairs of InDel marker primers were designed by comparing the whole-genome re-sequencing data with the sequence of the '02-12' reference genome.

These InDel marker primers were used to screen for polymorphisms between the parents. Ultimately, 58 of the 211 pairs of primers revealed polymorphisms, with a polymorphic rate of $27.5 \%$. The polymorphisms were further screened in two the bulks of the $F_{2}$ population, and only BoID4814, BoID4826 and BoID4837 exhibited polymorphisms between the two bulks. The three markers were preliminarily located on chromosome C09 according to the marker location in the reference genome.

Subsequently, 41 new additional InDel markers near the three polymorphic primers were designed, 26 of which showed polymorphisms. Only co-dominant markers with clear and stable amplification were chosen for further analysis in the $\mathrm{F}_{2}$ and $\mathrm{BC}_{1} \mathrm{P}_{1}$ populations. A genetic map comprising 16 InDel markers (Table 2) was constructed using MapDraw [26] (Fig. 2a). InDel markers M17 and BoID4714 were found to be closest to $\mathrm{BoPr}$, flanking the gene at genetic distances of $4.3 \mathrm{cM}$ and $1.5 \mathrm{cM}$,

Table 1 The Chi-square $\left(x^{2}\right)$ goodness-of-fit test ratios of leaf color segregation in $\mathrm{BC}$ and $\mathrm{F}_{2}$ populations

\begin{tabular}{|c|c|c|c|c|c|}
\hline Populations & Total plants number & Number of purple leaf individuals* & Number of white leaf individuals & Expected ratio & $x^{2 a}$ \\
\hline$F_{1}$ & 16 & 16 & 0 & - & - \\
\hline $\mathrm{F}_{2}$ & 1008 & 750 & 258 & 3:1 & 0.19 \\
\hline $\mathrm{BC}_{1} \mathrm{P}_{1}$ & 2034 & 1040 & 994 & 1:1 & 0.52 \\
\hline $\mathrm{BC}_{1} \mathrm{P}_{2}$ & 200 & 200 & 0 & - & - \\
\hline
\end{tabular}

*Purple plants and white plants were determined by visual inspection

${ }^{a} X^{2}>X_{0.05}^{2}=3.84$ was considered significant 
Table 2 The InDel primer sequences used in this study

\begin{tabular}{|c|c|c|c|}
\hline Primer name & Physical distance (bp) (02-12) & Forward primer sequence $\left(5^{\prime}-3^{\prime}\right)$ & Reverse primer sequence $\left(3^{\prime}-5^{\prime}\right)$ \\
\hline BolD4673 & C09:4123400 & GAATCGAGACAGAACCGTAT & TAACGTTAACCGGATTGG \\
\hline BolD4677 & C09:4347473 & TTAGCGTTTGTGTATTACCG & AAAGAACACAGAGGTTGGA \\
\hline BolD4697 & C09:5350367 & GGCTTTCTATCTGTCAAAAGG & GTTGGAGATTITCTATCCGA \\
\hline BolD4704 & C09:5830712 & TAATATTTGCGAGTGGAAGC & ATCCAGAACCGTCAATCTAA \\
\hline BolD4707 & C09:5940678 & GTTTCACCCTITGATCCTIT & TTCGCACCTTATCAAGTAGAG \\
\hline M1 & C09:5943643 & TTGAGCTGCTTCCTITAGTC & ACAGGAGTGGCATTTACATC \\
\hline M15 & C09:6139366 & CTTACACGAACCTTCTCTCG & GGCCTGCATATAAACCTCTT \\
\hline M17 & C09:6312350 & GAGGAGTCTACATGCGTTC & TTGAGGGTAAAGTAGACGGA \\
\hline BolD4714 & C09:6592994 & GCCTTAGCATCCAGAGATTA & ACGTCACAACGCTAATTACA \\
\hline BolD4717 & C09:7100587 & TCCTGGATACGAAGTACCTG & TCCTAGAAACTTGTTGTCGC \\
\hline BolD4794 & C09:13019067 & CATACTTGGAAGGAGCTTTG & CTCACAGTTTCTCCTITTGG \\
\hline BolD4798 & C09:13119313 & CGGATTAACACAGTGAAGAAG & AGATTTGACCTTAGAAGCG \\
\hline BolD4805 & C09:13318893 & ATATCGTCTGGCCCTCTATT & AGAACCCACAGAGACATCAC \\
\hline BolD4814 & C09:14085188 & CCTTGGGATTTACAAGGTACT & GAGTAATCGAGAATTATGAGCC \\
\hline BolD4837 & C09:18142750 & TGATACCTTTTGTCGAGCTT & ATTTGGGGTTGGTAGAAATC \\
\hline BolD4863 & C09:20025875 & AGCAGTGCATGATACAAATG & CGGGCTGTCTAAATCATTA \\
\hline Primer name & Physical distance (bp) (TO1000) & Forward primer sequence $\left(5^{\prime}-3^{\prime}\right)$ & Reverse primer sequence $\left(3^{\prime}-5^{\prime}\right)$ \\
\hline BRID399 & C09:10788227 & GGTTGGATTAAGATTGCTG & СTCCACCGTCATTGTATCAT \\
\hline BRID471 & C09:16850910 & TCTAAAAGGAGAAGCCAGAA & GAGGGGAGATGAGGTTACT \\
\hline BRID472 & C09:16879357 & GTTGAGTTGTITGGGAG & GACTTGTAGCATTTGTCGTG \\
\hline BRID482 & C09:17010450 & CATGCATTGAAAGTGTTGTC & AACTGAGCTTTCACACTGGT \\
\hline BRID485 & C09:17102497 & CTTCTTGGAGGTCTCTTGTG & TGCACATTAAAACGGTAGG \\
\hline BRID490 & C09:17147250 & TACTTGCATCAAATGTTGGG & GCACAGACTCATCTCCTTTC \\
\hline BRID493 & C09:17167025 & AGCACTGAGACTACCCTTGA & CAGCTTTGTCTTGTGTCTGA \\
\hline BRID494 & C09:17205726 & CGCCATATGAATAAAGGAAC & ACGAAGTCAACAAACAGCTT \\
\hline BRID499 & C09:17500985 & ATGCGATGATGAGATAGCTT & AGATCCACTTCAATCCAATG \\
\hline BRID505 & C09:17643567 & AACACATATTCCCGTCAAAC & GGAAAAGTGTGTTITGGG \\
\hline BRID517 & C09:17879063 & AAATCATCCAAACCACTGTC & GTGCCTCTACTAGTTITGGG \\
\hline BRID530 & C09:18485633 & TTCAAGACTCTCCAGCTCAT & CAAGAGAAAGACTGGTTCGT \\
\hline
\end{tabular}

respectively. Based on marker locations in the reference genome '02-12', BoPr is located on chromosome C09. The interval between the two markers is $280 \mathrm{~kb}$ (6,312,350-6,592,994 bp).

\section{Fine mapping of the purple leaf gene}

The $280 \mathrm{~kb}$ interval spans two scaffolds (Scaffold000195_ P2, Scaffold000050), and no polymorphic marker between the parents was found in this narrow interval. Moreover, the genetic distance for this $280 \mathrm{~kb}$ interval was calculated to be $5.8 \mathrm{cM}, 12$ times higher than the usual level ( $600 \mathrm{~kb} / \mathrm{cM})$. Thus, another reference genome, 'TO1000' [11], was used to determine the accuracy of this interval. Blast alignment analysis showed the physical distance between markers M17 (7,590,215-7,590,234 bp) and BoID4714 (20,327,191-20,327,211 bp) to be approximately
12.73 $\mathrm{Mb}$ in the 'TO1000' reference genome, indicating possible assembly errors in the reference genome '0212 ' or 'TO1000'. To determine whether this $12.73 \mathrm{Mb}$ interval is linked to the $\mathrm{BoPr}$ gene, 70 pairs of InDel marker primers were designed based on the 'TO1000' reference genome. Polymorphisms between the two bulks were found for 12 of the 70 pairs, and these were used to analyze the $\mathrm{BC}_{1} \mathrm{P}_{1}$ and $\mathrm{F}_{2}$ populations. $\mathrm{A}$ genetic map comprising 12 InDel markers (Table 2) was constructed using MapDraw (Fig. 2b). InDel markers BRID485 and BRID490 were found to be the closest to $\mathrm{BoPr}$, flanking the gene at genetic distances of $0.10 \mathrm{cM}$ and $0.20 \mathrm{cM}$, respectively. Based on marker locations in the reference genome 'TO1000', the interval between BRID485 and BRID490 is $44.8 \mathrm{~kb}(17,102,497-$ $17,147,250 \mathrm{bp})$. 


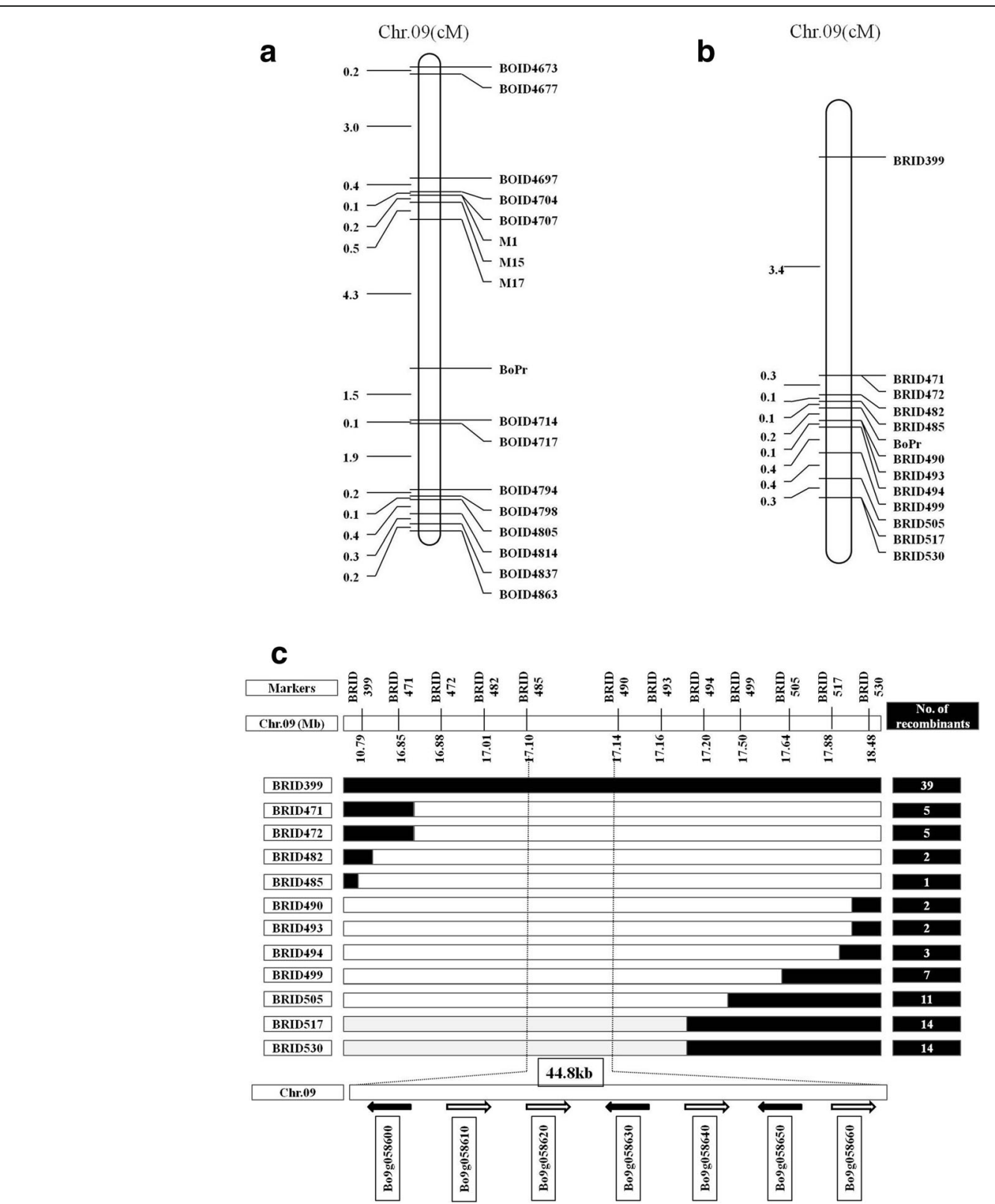

Fig. 2 a Preliminary mapping of $B o P r$, units: $\mathrm{CM}$. b Fine mapping of $B \circ P r$, units: $\mathrm{CM}$. c Fine mapping using the $\mathrm{BC}_{1} \mathrm{P}_{1}$ population with 2034 plants. The BoPr gene was delimited to an interval between BRID485 and BRID490, with an estimated length of $44.8 \mathrm{~kb}$, seven genes were annotated between markers BRID485 and BRID490 based on the reference genome sequence. The genetic structure for each recombinant type is depicted as white for homozygous white leaf alleles, black rectangles for heterozygous alleles, respectively. The relative positions of markers on C09 were determined according to the TO1000 genome sequence

\section{Prediction and analysis of the candidate gene}

Based on the 'TO1000' reference genome (http://plants. ensembl.org/Brassica_oleracea) (Parkin et al. 2014), seven genes were identified in the $44.8 \mathrm{~kb}$ region (Table 3 ). According to domain annotations from InterPro and BLASTX (best hit) analyses, four of these seven genes have not been annotated (Table 3). The other three genes are as follows: Bo9g058600 (homologous gene AT5G42790) encoding the largest proteasomal subunit; Bo9g058660 (homologous gene AT5G42810) encoding inositol tetrapentaphosphate 2-kinase; Bo9g058630 (homologous gene AT5G42800) encoding dihydroflavonol 4-reductase (DFR), which catalyzes conversion of dihydroquercetin to leucocyanidin in anthocyanin biosynthesis [29]. Thus, we tentatively designated $B o 9 g 058630$ as the candidate gene controlling the purple leaf color in ornamental kale. 
Table 3 Annotation of B. oleracea genes in the candidate region

\begin{tabular}{lllllll}
\hline Bol ID & E-value & Bo genes $^{\mathrm{b}}$ & Gene position on C09 $^{\mathrm{c}}$ & AT ID $^{\mathrm{d}}$ & E-value & AT GO $^{\mathrm{e}}$ annotation \\
\hline Bol035270 & 0.0 & Bo9g058600 & $17102783-17104636 \mathrm{bp}$ & AT5G42790 & 0.0 & the largest subunit of proteasome \\
- & - & Bo9g058610 & $17111283-17112572 \mathrm{bp}$ & - & - & - \\
- & - & Bo9g058620 & $17113341-17114372 \mathrm{bp}$ & - & - & - \\
Bol035269 & 0.0 & Bo9g058630 & $17116312-17117891 \mathrm{bp}$ & AT5G42800 & 0.0 & dihydroflavonol reductase \\
- & - & Bo9g058640 & $17124223-17124381 \mathrm{bp}$ & - & - & - \\
- & - & Bo9g058650 & $17137677-17138809 \mathrm{bp}$ & - & - & - \\
Bol035268 & 0.0 & Bo9g058660 & $17145032-17147070 \mathrm{bp}$ & AT5G42810 & 0.0 & Encodes an inositol tetra-/pentaphosphate \\
& & & & & & 2-kinase \\
\hline
\end{tabular}

${ }^{a} B$. oleracea homologous genes in the candidate region (reference genome '02-12')

beven $B$. oleracea genes in the candidate region. The likely leaf color genes and their information are indicated in bold (reference genome 'TO1000')

'The physical position of seven B. oleracea genes on chromosome C09 (reference genome 'TO1000')

${ }^{\mathrm{d}}$ The best hits of the seven $B$. oleracea genes compared to $A$. thaliana (AT)

${ }^{\mathrm{e}} \mathrm{GO}$ annotations for seven Bo to AT best-hit genes obtained from TAIR

Primer pairs were designed spanning the full length of Bo9g058630 (Table 4), and PCR was performed using genomic DNA of W1827 and P1835 as the template. Based on agarose gel electrophoresis (Fig. 3), amplicons of approximately $4.0 \mathrm{~kb}$ for W1827 and approximately $2.0 \mathrm{~kb}$ for P1835 were obtained. Sequencing revealed that the full-length $B o 9 g 058630$ sequence in purple-leaf P1835 is $1580 \mathrm{bp}$, whereas that in white-leaf W1827 is 3856 bp. Compared with Bo9g058630 in P1835, a 124 bp deletion, a $2400 \mathrm{bp}$ insertion at nucleotide 68 and four SNPs are present in W1827 (sequences of W1827 and P1835 are supplied in Additional file 1: Supplementary 1). Polymorphism of the candidate gene $B o 9 g 058630$ was further confirmed in the segregating population.

\section{Discussion}

\section{Mapping of the purple leaf gene}

Purple-leaf traits have been studied in several species, such as rice [30,31], tetraploid wheat [32], Brassica rapa [7], and carrot [9, 33]. Some genes related to anthocyanins, which might be responsible for purple leaf color, have been reported in Brassica, including BrPur in $B$. rapa [7], BnaA.PL1 in B. napus [8], and the Re and Pi genes in B. oleracea [5, 9].

Ren et al. [5] reported that markers C9Z90 (C09:18,377,796 bp) and C9Z94 (C09:6,872,051 bp) are tightly linked to $R e$, which controls the red-leaf phenotype in kale [5]. The red-leaf phenotype is similar with the purple phenotype of the parents used in the present study. Based on reference genome 'TO1000', our results show that C9Z90 is located between InDel markers BRID517 (17,879,063 bp) and BRID530 (18,485,633 bp) and that C9Z94 is located between InDel markers

Table 4 Primers used for full-length candidate gene cloning

\begin{tabular}{ll}
\hline Primers & Primers sequences $\left(5^{\prime}-3^{\prime}\right)$ \\
\hline Bo630 & GTCCACAACACTTTCATACAA/TTCCCAAAGCATAATCCATCT \\
\hline
\end{tabular}

BoID4704 (6,418,130 bp) and BoID4707 (7,177,017 bp). This indicates that the mapping interval in Ren et al. [5] is larger than ours. Furthermore, the distance between the Re gene and the closest markers are $2.0 \mathrm{cM}$ for C9Z94 and $0.3 \mathrm{cM}$ for C9Z90 [5] but $6.1 \mathrm{cM}$ for BoID4704 and $1.1 \mathrm{cM}$ for BRID517 in our mapping population, which may be caused by different mapping populations. In our study, however, the $\mathrm{BoPr}$ gene was successfully fine mapped to a $44.8-\mathrm{kb}$ interval based in the 'TO1000' reference genome.

For the mapping population, $\mathrm{F}_{2}$ and $\mathrm{BC}_{1}$ populations are usually constructed for mapping important agronomic traits. In this study, for markers far away from the candidate gene, the recombination rate of the $F_{2}$ population was larger than that of the $\mathrm{BC}_{1} \mathrm{P}_{1}$ population; however, the opposite case was true for markers close to the candidate region (Additional file 2: Table S1). The closest flanking markers BRID485 and BRID490 were all screened from the $\mathrm{BC}_{1} \mathrm{P}_{1}$ population, with no

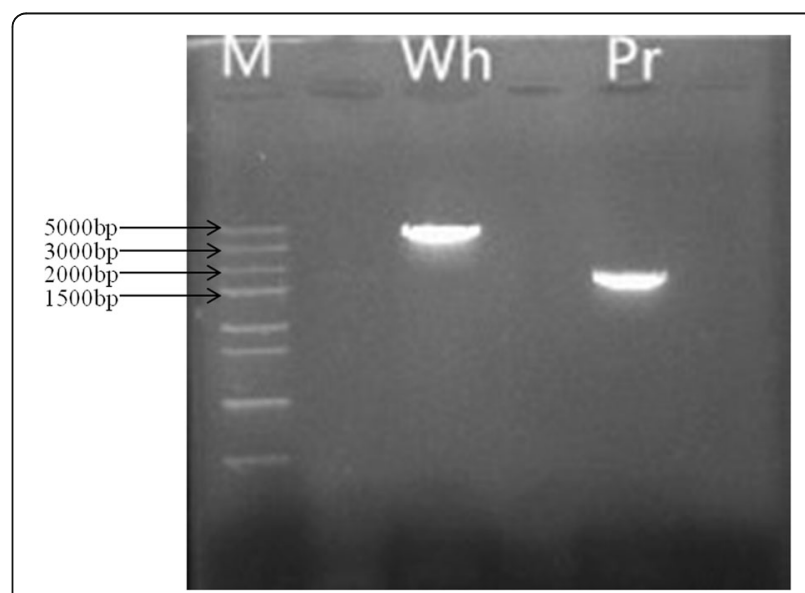

Fig. 3 PCR products of amplicon Bo630 (isolated by agarose gel electrophoresis); $M$ represents the DNA ladder, Pr is the inbred line P1835 with purple leaves, Wh is the inbred line W1827 with white leaves 
recombinants in the $\mathrm{F}_{2}$ population. Furthermore, the rate of recessive individuals in the $\mathrm{BC}_{1} \mathrm{P}_{1}$ populations was $1 / 2$, which was twice that of the $F_{2}$ population. Therefore, we used the large $\mathrm{BC}_{1} \mathrm{P}_{1}$ population to fine map the candidate gene.

\section{Possible assembly errors in cabbage reference genome '02-12'}

With the development of technology, large amounts of data are produced by genome sequencing, though genome assemblies based on these data are often woefully incomplete. Although the Nipponbare reference sequence (RefSeq) exhibits the best quality among crop genomes, it still contains many assembly errors and gaps [34, 35]. Genome sequencing has been completed in three species of Brassica: B.napus [36], B. rapa [37] and $B$. oleracea $[10,11]$. Some assembly problems have been reported. For example, Lee et al. [23] revised the '02-12' reference genome assembly when they mapped clubroot resistance QTLs using genotyping-by-sequencing; new positions for $27 \mathrm{v}$-blocks and $10 \mathrm{~s}$-blocks and several inversions of some alphabetically named blocks in reference genome '02-12' and two mis-anchored sequence scaffolds in reference genome 'TO1000' were identified. In addition, Liu et al. [15] found possible assembly errors in '02-12' while mapping a yellow-green leaf mutant.

In this study, the recombination rate of markers M17 and BoID4714 in '02-12' [10] $(48 \mathrm{~kb} / \mathrm{cM})$ was found to be almost 12 times higher than the usual level in the cabbage genome $(\sim 600 \mathrm{~kb} / \mathrm{cM})$ in preliminary mapping. In 'TO1000' the primary mapping interval was found to be $12.7 \mathrm{Mb}(\sim 1760 \mathrm{~kb} / \mathrm{cM})$. Based on the 'TO1000' genome, the $B o P r$ gene was fine mapped to a $44.8 \mathrm{~kb}$ interval, but according to primary mapping, this $44.8 \mathrm{~kb}$ is not located in the $280 \mathrm{~kb}$ region but is on an unanchored scaffold (Scaffold000035_P2) of '02-12'. Thus, the mapping results suggested possible assembly error and the potential location of the unanchored Scaffold000035_P2 in the $02-12$ reference genome. However, this scaffold is only $1.5 \mathrm{Mb}$. More unanchored scaffolds could be detected within this interval in the future if PacBio, a thirdgeneration sequencing platform, is applied to improve the reference genome of ' $02-12$ '. These results will contribute to the improvement of the cabbage genome and provide guidance for map-based cloning of other genes in this region.

\section{The DFR gene in anthocyanin biosynthetic pathways}

The biosynthetic pathways of anthocyanins and related genes have been well characterized, and DFR is a key enzyme in the anthocyanin biosynthetic pathway [38]. In characterizing DFR genes, Ahmed et al. found that these genes are associated with cold and freezing stresses in B. rapa [39]. Guo et al. identified 73 anthocyanin biosynthetic genes, locating the DFR gene on chromosome A09, named BrDFR (Bra027457), in B. rapa [40].

In our study, Bo9g058630 was found to be homologous to Arabidopsis thaliana AT5G42800, which encodes DFR. DFRs utilizing the three primary dihydroflavonol substrates have been characterized. Expression of DFR clones together with plant-specific 4-coumaroyl: CoA ligase, chalcone synthase, chalcone isomerase, and flavanone 3-hydroxylase in $E$. coli resulted in the synthesis of various levels of pelargonidin and could be used for engineering of other bioactive flavonoids, such as flavan-3ols [41]. The purple-leaf trait of ornamental kale is largely attributed to various anthocyanin components [2], and sequence alignment showed that the function of Bo9g058630 in the white-leaf line W1835 is disrupted by two InDels. Furthermore, we designed a co-dominant marker based on sequence differences between W1835 and P1827, and this marker co-segregated with the phenotype of all recessive individuals in the $\mathrm{F}_{2}$ and $\mathrm{BC}_{1}$ populations. Thus, we suggest that Bo9g058630 is the most likely candidate gene for the purple-leaf trait. However, further work involving transformation is needed to verify whether the function of this gene is responsible for purple leaves in kale.

\section{Conclusions}

Inheritance of purple leaves in kale was found to be controlled by a single dominant gene, $\mathrm{BoPr}$, and this gene was mapped to a $44.8 \mathrm{~kb}$ interval (reference genome 'TO1000') on chromosome C09. InDel markers BRID485 and BRID490 are closest to $\mathrm{BoPr}$, flanking the gene at genetic distances of $0.1 \mathrm{cM}$ and $0.2 \mathrm{cM}$. In the finemapping region, only Bo9g058630 showed high homology to AT5G42800 (dihydroflavonol reductase), which was identified as a candidate gene for $B o P r$. This study lays a foundation for the cloning of the gene $\mathrm{BoPr}$ as well as further function analyses.

\section{Additional files}

Additional file 1: Supplementary 1. Sequences of W1827 and P1835. (DOC 29 kb)

Additional file 2: Table $\mathbf{S} 1$. The recombination rate of markers far away from the candidate gene in the $\mathrm{F}_{2}$ and $\mathrm{BC}_{1} \mathrm{P}_{1}$ population. (DOCX $13 \mathrm{~kb}$ )

Abbreviations

BRAD: Brassica Database; BSA: Bulked segregant analysis; InDel: Insertion/ deletion; PCR: Polymerase chain reaction; QTL: Quantitative trait locus; SNP: Single nucleotide polymorphism

Acknowledgments

Not applicable.

Funding

This work was financially supported by grants from the National Natural Science Foundation of China (31572141), the Major State Research Development 
Program (2016YFD0101702), the Science and Technology Innovation Program of Chinese Academy of Agricultural Sciences (CAAS-ASTIP-IVFCAAS) and the earmarked fund for the Modern Agro-Industry Technology Research System, China (nycytx-35-gw01). This work was performed in the Key Laboratory of Biology and Genetic Improvement of Horticultural Crops, Ministry of Agriculture, Beijing 100081, People's Republic of China.

\section{Availability of data and materials}

The reference B. oleracea genome sequence was obtained from Brassica Database (http://brassicadb.org); the reference TO1000 sequence was obtained from the genome sequence (http://plants.ensembl.org/Brassica_oleracea). As one of the data owners, we confirm that we have full permission to use the genome sequence for the purposes of this study (i.e., candidate gene identification and characterization). The use of the reference genome for these purposes was approved by all data owners.

\section{Authors' contributions}

$X L$ developed the $F_{2}$ and $B C$ populations and wrote and revised the manuscript. $H Y$, FH, and ZL isolated the samples, performed the marker assays, and analyzed the marker data. FH, ZF, LY, MZ, HL, YL, ZL and YZ conceived the study and critically reviewed the manuscript. $X \mathrm{~L}, \mathrm{CC}$ and $\mathrm{BG}$ analyzed the sequencing data and designed the InDel primers. All authors read and approved the final manuscript.

\section{Competing interests}

The authors declare that they have no competing interests.

\section{Consent for publication}

Not applicable.

Ethics approval and consent to participate

Not applicable.

\section{Publisher's Note}

Springer Nature remains neutral with regard to jurisdictional claims in published maps and institutional affiliations.

Received: 6 September 2016 Accepted: 7 March 2017

Published online: 14 March 2017

\section{References}

1. Schmidt S, Zietz M, Schreiner M, Rohn S, Kroh LW, Krumbein A. Genotypic and climatic influences on the concentration and composition of flavonoids in kale (Brassica oleracea var. sabellica). Food Chem. 2010;119:1293-9.

2. Zhang B, Hu ZL, Zhang YJ, Li YL, Zhou S, Chen GP. A putative functional MYB transcription factor induced by low temperature regulates anthocyanin biosynthesis in purple kale. (Brassica oleracea var acephala f. tricolor). Plant Cell Rep. 2012;31:281-9.

3. de Gaulejac NSC, Glories Y, Vivas N. Free radical scavenging effect of anthocyanins in red wines. Food Res Int. 1999;32:327-33.

4. Yun JM, Afaq F, Khan N, Mukhtar H. Delphinidin, an anthocyanidin in pigmented fruits and vegetables, induces apoptosis and cell cycle arrest in human colon cancer HCT116 cells. Mol Carcinog. 2009;48:260-70.

5. Ren J, Liu ZY, Niu RQ, Feng H. Mapping of Re, a gene conferring the red leaf trait in ornamental kale (Brassica oleracea. L. var. acephala). Plant Breed. 2015;134:494-500.

6. Luo YX, Du DZ, Fu G, Xu L, Li XP, Xing XR, Yao YM, Zhang XM, Zhao Z, Liu HD. Inheritance of leaf color and sequencerelated amplified polymorphic (SRAP) molecular markers linked to the leaf color gene in Brassica juncea. Afr J Biotechnol. 2011;10:14724-30.

7. Wang WH, Zhang DS, Yu SC, Liu J, Wang D, Yu YJ, Zhao XY, Lu GX, Su TB, Zhang FL. Mapping the Br Pur gene for purple leaf color on linkage group A03 of Brassica rapa. Euphytica. 2014;199:293-302.

8. Li HB, Zhu LX, Yuan GG, Heng SP, Yi B, Ma CZ, Shen JX, Tu JX, Fu TD, Wen J. Fine mapping and candidate gene analysis of an anthocyanin-rich gene BnaA.PL1, conferring purple leaves in Brassica napus, L. Mol Genet Genomics. 2016;291:1523-34

9. Zhu PF, Cheng MM, Feng X, Xiong Y, Liu C, Kang YH. Mapping of Pi, a gene conferring pink leaf in ornamental kale (Brassica oleracea, L. var. acephala, DC). Euphytica. 2016;207:377-85.
10. Liu S, Liu Y, Yang X, Tong C, Edwards D, Parkin IA, et al. The Brassica oleracea genome reveals the asymmetrical evolution of polyploid genomes. Nat Commun. 2014;5:3930.

11. Parkin IA, Koh C, Tang H, Robinson SJ, Kagale S, Clarke WE, et al. Transcriptome and methylome profiling reveals relics of genome dominance in the mesopolyploid Brassica oleracea. Genome Biol. 2014;15:R77.

12. Lv HH, Yang LM, Kang JG, Wang QB, Wang XW, Fang ZY, et al. Development of InDel markers linked to Fusarium wilt resistance in cabbage. Mol Breed. 2013:32:961-7.

13. Lv HH, Fang ZY, Yang LM, Zhang YY, Wang QB, Liu YM, et al. Mapping and analysis of a novel candidate Fusarium wilt resistance gene FOC1 in Brassica oleracea. BMC Genom. 2014;15:1094.

14. Han FQ, Yang C, Fang ZY, Yang LM, Zhuang M, Lv HH, Zhang YY, et al. Inheritance and InDel markers closely linked to petal color gene (cpc-1) in Brassica oleracea. Mol Breed. 2015:35:1-8.

15. Liu XP, Yang C, Han FQ, Fang ZY, Yang LM, Zhuang M, et al. Genetics and fine mapping of a yellow-green leaf gene (ygl-1) in cabbage (Brassica oleracea var. capitata L.). Mol Breed. 2016;36:1-8.

16. Lv HH, Wang QB, Zhang YY, Yang LM, Fang ZY, Wang XW, et al. Linkage map construction using InDel and SSR markers and QTL analysis of heading traits in cabbage. Mol Breed. 2014:34:87-98.

17. Pang WX, Li XN, Choi SR, Nguyen VD, Dhandapani V, Kim YY, et al. Mapping QTLs of resistance to head splitting in cabbage. (Brassica oleracea L. var. capitata L.). Mol Breed. 2015;35:1-12.

18. Su YB, Liu YM, Li ZS, Fang ZY, Yang LM, Zhuang M, Zhang YY. QTL analysis of head splitting resistance in cabbage (Brassica oleracea L. var. capitata) using using SSR and InDel makers based on whole-genome Re-sequencing. PLoS One. 2015;10:e0138073.

19. Ramchiary N, Pang W, Nguyen VD, Li X, Choi SR, Kumar A, et al. Quantitative trait loci mapping of partial resistance to diamondback moth in cabbage (Brassica oleracea L). Theor Appl Genet. 2015;128:1209-18.

20. Mei J, Ding Y, Lu K, Wei D, Liu Y, Disi JO, et al. Identification of genomic regions involved in resistance against Sclerotinia sclerotiorum from wild Brassica oleracea. Theor Appl Genet. 2013;126:549-56.

21. Kifuji Y, Hanzawa H, Terasawa Y, Nishio T. QTL analysis of black rot resistance in cabbage using newly developed EST-SNP markers. Euphytica. 2013;190:289-95.

22. Lee J, Izzah NK, Jayakodi M, Perumal S, Joh HJ, Lee HJ, et al. Genome-wide SNP identification and QTL mapping for black rot resistance in cabbage. BMC Plant Biol. 2015;15:32.

23. Lee J, Izzah NK, Choi BS, Joh HJ, Lee SC, et al. Genotyping-by-sequencing map permits identification of clubroot resistance QTLS and revision of the reference genome assembly in cabbage (Brassica oleracea L.). DNA Res. 2015;14:S113.

24. Ronaghi $M$, Uhlén $M$, Nyrén $P$. A sequencing method based on real-time pyrophosphate. Science. 1998;281:363-5.

25. Murray MG, Thompson WF. Rapid isolation of high molecular weight plant DNA. Nucleic Acids Res. 1980;8:4321-5.

26. Michelmore RW, Paran I, Kesseli RV. Identification of markers linked to disease-resistance genes by bulked segregant analysis: a rapid method to detect markers in specific genomic regions by using segregating populations. Proc Natl Acad Sci U S A. 1991;88:9828-32.

27. Kosambi DD. The estimation of map distances from recombination values Ann Eugen. 1943;12:172-5.

28. Liu RH, Meng JL. MapDraw: a microsoft excel macro for drawing genetic linkage maps based on given genetic linkage data. Hereditas. 2003;25:317-21 [in Chinese].

29. Shirley BW, Hanley S, Goodman HM. Effects of ionizing radiation on a plant genome: analysis of two Arabidopsis transparent testa mutations. Plant Cell. 1992:4:333-47.

30. Kinoshita T, Takamure I. Gene mapping of the first and second linkage groups in rice. Journal Faculty of Agriculture Hokkaido University. 1990;64:208-17

31. Sakamoto W, Murata M, Maekawa M. Complex organization of the rice purple leaf locus involved in tissue-specific accumulation of anthocyanin. In: Kush GS, Brar DS, Hardy B, editors. Advances in rice genetics. Supplement to Rice Genetics IV. Proceedings of the Fourth International Rice Genetics Symposium, 22-27 Oct 2000, Los Banos: International Rice Research Institute; 2003. p. 475-7.

32. Khlestkina EK, Röder MS, Börner A. Mapping genes controlling anthocyanin pigmentation on the glume and pericarp in tetraploid wheat (Triticum durum L.). Euphytica. 2010;171:65-9. 
33. Simon PW. High-resolution mapping of root and leaf anthocyanin pigmentation QTL in carrot. Proceedings, Plant \& Animal Genome, January 10-14, 2015

34. Deng Y, Pan Y, Luo M. Detection and correction of assembly errors of rice Nipponbare reference sequence. Plant Biol (Stuttg). 2014;16:643-50.

35. Denton JF, Lugo-Martinez J, Tucker AE, Schrider DR, Warren WC, Hahn MW. Extensive error in the number of genes inferred from draft genome assemblies. PLoS Comput Biol. 2014;10:e1003998.

36. Chalhoub B, Denoeud F, Liu S, Parkin IA, Tang H, Wang X, et al. Plant genetics. Early allopolyploid evolution in the post-Neolithic Brassica napus oilseed genome. Science. 2014;345:950-3.

37. Wang $X$, Wang H, Wang J, Sun R, Wu J, Liu S, et al. The genome of the mesopolyploid crop species Brassica rapa. Nat Genet. 2011:43:1035-9.

38. Holton TA, Cornish EC. Genetics and biochemistry of anthocyanin biosynthesis. Plant Cell. 1995;7:1071-83.

39. Ahmed NU, Park JI, Jung HJ, Yang TJ, Hur Y, Nou IS. Characterization of dihydroflavonol 4-reductase (DFR) genes and their association with cold and freezing stress in Brassica rapa. Gene. 2014;550:46-55.

40. Guo N, Cheng F, Wu J, Liu B, Zheng S, Liang J, Wang XW. Anthocyanin biosynthetic genes in Brassica rapa. BMC Genomics. 2014;15:426.

41. Leonard E, Yan Y, Fowler ZL, Li Z, Lim CG, Lim KH, Koffas MAG. Strain improvement of recombinant Escherichia coli for efficient production of plant flavonoids. Mol Pharm. 2008:5:257-65.

\section{Submit your next manuscript to BioMed Central} and we will help you at every step:

- We accept pre-submission inquiries

- Our selector tool helps you to find the most relevant journal

- We provide round the clock customer support

- Convenient online submission

- Thorough peer review

- Inclusion in PubMed and all major indexing services

- Maximum visibility for your research

Submit your manuscript at www.biomedcentral.com/submit 